\section{JTI}

JOURNAL OF

TRAUMA AND INJURY

\title{
Management and Outcome of Patients with Acetabular Fractures: Associated Injuries and Prognostic Factors
}

\author{
Do-Hyun Yeo, M.D., Jong-Keon Oh, M.D., Ph.D., Jae-Woo Cho, M.D., \\ Beom-Soo Kim, M.D.
}

Department of Orthopedic Surgery, Guro Hospital, Korea University Medical Center, Seoul, Korea

Received: June 2, 2018

Revised: October 25, 2018

Accepted: November 5, 2018

\section{Correspondence to}

Jong-Keon Oh, M.D., Ph.D.

Department of Orthopedic Surgery, Guro Hospital, Korea University Medical Center,

148 Gurodong-ro, Guro-gu, Seoul 08308 Korea

Tel: $+82-2-2626-1114$

Fax: +82-2-2626-1163

E-mail:jkoh@korea.ac.kr
Purpose: The aim of this study was to determine which factors contribute to the surgical treatment outcomes of acetabular fractures. Simultaneously, we aim to report on the treatment results after our hospital was designated as the focused training center for trauma.

Methods: We conducted a retrospective review of all patients who experienced acetabular fractures from January 1, 2014 to May 1, 2017 and visited our hospital. Patients who had associated pelvic ring fractures or were lost to the one-year follow-up were excluded; a total of 37 fractures were evaluated. We evaluated the clinical results using the scoring system of Merle d'Aubigné (MDA) and grade of Brooker for heterotopic ossification.

Results: Thirty-seven patients (31 men and 6 women) were identified. The mean injury severity score (ISS) was 8.7 , with $32.4 \%$ of patients having a score $>15$. The average blood transfusion in the first 24 hours was 0.54 pints. Falling was the most common injury mechanism (32.4\%). Chest injury was the most common associated injury (16.2\%), followed by head injury (13.5\%). The posterior wall and both column fracture were the most common (37.8\%) fracture patterns. Excellent and good clinical grades of MDA included 28 patients $(75.6 \%)$ and fair and poor grades included nine (24.3\%), respectively. Four patients were diagnosed with a post-operative infection (10.8\%); one out of four patients who had co-morbidity died (2.7\%), and another patient underwent a replacement surgery (2.7\%). Multivariate analysis showed that age and operation time were associated with MDA. In addition, operation time and ISS were significant co-factors of the Brooker grade.

Conclusions: Korea University Guro Hospital showed similar treatment results of acetabular fractures compared to other publications. The age and operation time were co-factors of the clinical outcome of this fracture. Additionally, increased operation time and injury severity score were suggested to increase the Brooker grade.

Keywords: Fractures, Acetabulum; Associated injuries; Injury severity score; Risk factors

Copyright $\odot 2019$ The Korean Society of Trauma

This is an Open Access article distributed under the terms of the Creative Commons Attribution Non-Commercial License (http://creativecommons.org/licenses/by-nc/4.0/) which permits unrestricted noncommercial use, distribution, and reproduction in any medium, provided the original work is properly cited. 


\section{INTRODUCTION}

Management of acetabular fractures is challenging for surgeons because they are uncommon and have complex anatomy [1-3]. Moreover, this injury is usually caused by high-energy trauma, so there is a high risk of multiple associated injuries. Associated injuries are the major factor of the mortality in pelvic and acetabular fractures [4]. However, the mortality of acetabular fractures is significantly lower than that of pelvic ring injuries, making it difficult to study the relationship between the mortality and associated injuries in acetabular fracture [2]. On the other hand, factors related to the functional outcome are well established. Many authors reported that the quality of reduction and the fracture type are the main factors for the functional outcome of this fracture [5,6]. Most of these studies have focused on the fracture itself or the surgical technique. We reasoned that associated injuries of this fracture could be related with functional outcomes; therefore, is worth investigating the predictability of associated injuries for the functional outcome from a multi-disciplinary perspective. In this study, we reviewed our 3-year history of acetabular fractures, since Korea University Guro Hospital was designated as the focused training center for trauma and analyzed factors that can influence the short-term results of this fracture.

\section{METHODS}

The study was conducted at Korea University Guro Hospital, which had the focused training center of trauma (FTCT). The approval of institution's ethical review board was obtained prior to initiation of the study. We retrospectively reviewed 47 patients who were diagnosed with acetabular fractures from January 1, 2014 (beginning of the FTCT) to May 1, 2017 for 1-year mortality. The approach that was used depended on the fracture pattern. Patients who had associated pelvic ring injury [7], periprosthetic fracture [1] and those lost to follow-up [2] were excluded and a total of 37 patients were enrolled in our study.

The data collected for each patient included: demographics, injury severity score (ISS), mechanism of injury, acetabular fracture type, presence of associated injury, number of packed red blood cell (pRBC) transfusion, intensive care unit care, operation time, intraoperative blood loss, clinical outcomes, and mortality. The blood transfusion status was checked pre-, intra-, and post-operatively. The Judet and Letournel acetabular fracture classification was used. The presence of associated injuries was determined by reviewing emergency charts and the admission notes of each department. Open reduction and internal fixation were performed by two surgeons (J.K.O and J.W.C), who have more than 2 years of experience in the treatment of this fracture. Modified Stoppa approach with lateral window of the ilioinguinal approach and the Kocher-Langenbeck approach were used depending on the fracture patterns. We used reconstruction plates and screws to obtain stable fixation. Evaluation of the quality of the reduction was not recorded in this study because the correlation with poor clinical outcomes was already well-described and the aim of the present study is to identify the influence of associated injuries [5].

\section{Evaluation of clinical outcomes}

We evaluated patient function, post-operative development of arthritis, and complications. The clinical information of the most recent follow-up visit was used. A modified Merle d'Aubigné (MDA) and Postel clinical grading scale was utilized for functional outcome. The presence of post-operative arthritic changes was evaluated radiologically.

Postoperative infection, neurologic sequelae, osteonecrosis of the femoral head, and heterotopic ossification were documented as complications. Postoperative infection was divided into two groups: superficial and deep surgical site infection according to the Centers for Disease Control and Prevention/National Healthcare Safety Network (CDC/NHSN) [7]. While a superficial infection only involves the skin area, a deep infection involves not only the skin, but also the muscles and surrounding tissues. Neurologic sequelae was diagnosed by electromyogram. The osteonecrosis of the femoral head was confirmed by radiograph, magnetic resonance imaging, or bone scan if needed clinically. For the radiological assessment of the development of heterotopic ossification, the Brooker grade was used. 


\section{Statistical analysis}

All descriptive results were presented as the mean \pm standard deviation. Categorical data were analyzed with Fisher's exact test. These factors included ICU care within the patient's first 24 hours, presence of a head, chest, intra-abdominal, extremity, or urogenital injury, and femoral head fracture. The dependent variables consisted of postoperative infection, neurological sequelae, osteonecrosis of the femoral head, and heterotopic ossification. Other numerical data that could be used for multiple logistic regression analysis were accounted for simultaneously. These factors included patient age, ISS, number of pRBC transfusion, operation time, and intraoperative blood loss. The dependent variables were MDA and Brooker grade. Statistical analysis was performed using SPSS software version 20.0 (SPSS Inc., Chicago, IL, USA). A p-value of less than 0.05 was considered significant.

\section{RESULTS}

Demographic information and trauma scoring is listed in Table 1. Mean ISS (range) was 8.70 (2-33) and 5 patients (13.2\%) had results $>15$ points. The average blood transfusion in the first 24 hours was $0.54 \pm 1.74$ pints. Falling was the most common injury mechanism (32.4\%), followed by motor vehicle collision $(27.0 \%)$. These two mechanisms accounted for $59.4 \%$ of the total (Table 2). Chest injury was the most common associated injury (16.2\%), followed by head injury (13.5\%) and intra-abdominal injury (10.8\%) (Table 3). Fracture classifications according to Letournel [8] are shown in Table 4. The posterior wall and both column fractures were the most

Table 1. Demographic data and trauma scoring

\begin{tabular}{|lc|}
\hline & \multicolumn{1}{c|}{ Value } \\
\hline Age (years) & $46.86 \pm 15.1924(18-79)$ \\
Sex & $31(83.8)$ \\
Male & $6(16.2)$ \\
Female & $8.70 \pm 6.87(2-33)$ \\
ISS & $0.54 \pm 1.74(0-8)$ \\
pRBCs (within 24 hours) & \\
\hline
\end{tabular}

Values are presented as mean \pm standard deviation (range) or number (\%). ISS: injury severity score, pRBCs: packed red blood cells. common $(37.8 \%)$.

\section{Clinical results}

Clinical grades of MDA were: excellent (10;27\%), good $(18,48.6 \%)$, fair $(4 ; 10.8 \%)$, and poor $(5 ; 13.5 \%)$. There

Table 2. Mechanism of injury

\begin{tabular}{|lc|}
\hline Mechanism & Value \\
\hline Fall & $12(32.4)$ \\
\hline Motor vehicle collision & $10(27.0)$ \\
\hline Motorcycle collision injury & $7(18.9)$ \\
Slip & $4(10.8)$ \\
Heavy equipment accident & $2(5.4)$ \\
Pedestrian-struck by vehicle & $1(2.7)$ \\
Bicycle injury & $1(2.7)$ \\
\hline
\end{tabular}

Values are presented as number (\%).

Table 3. Associated injuries

\begin{tabular}{|lc|}
\hline & Value \\
\hline Head & $5(13.5)$ \\
\hline Chest & $6(16.2)$ \\
Intra-abdominal & $4(10.8)$ \\
Urogenital & $2(5.4)$ \\
Extremities & $15(40.5)$ \\
\hline
\end{tabular}

Values are presented as number (\%).

Table 4. Type of acetabular fractures according to the Judet-Letournel classification

\begin{tabular}{|lc|}
\hline Type & Value \\
\hline Elementary & $18(48.6)$ \\
Posterior wall & $14(37.8)$ \\
Posterior column & $-(0)$ \\
Anterior wall & $-(0)$ \\
Anterior column & $3(8.1)$ \\
Transverse & $1(2.7)$ \\
Associated & $19(51.4)$ \\
Posterior column+posterior wall & $2(5.4)$ \\
Transverse+posterior wall & $3(8.1)$ \\
T-shaped & $-(0)$ \\
Anterior column+posterior hemitransverse & $-(0)$ \\
Both column & $14(37.8)$ \\
\hline
\end{tabular}

Values are presented as number (\%). 
were four patients $(10.8 \%)$ who were diagnosed with post-operative infections; three had a deep infection and one had a superficial infection. One patient with a deep infection had a co-morbidity of diabetes and chronic renal disease and finally died 15 months postoperatively (2.7\%). The other patient underwent a total hip replacement $(2.7 \%)$ due to postoperative infection 6 months after surgery. The remaining patient with a deep infection presented an improved condition after surgical debridement. The patient with a superficial infection also improved by receiving medication without surgical management. Two patients had neurologic sequelae diagnosed by electromyography (5.4\%). Three patients developed osteonecrosis of the femoral head after the injury but did not require further surgery $(8.1 \%)$. The amount of heterotopic ossification was scored using the method described by Brooker et al. [9]. The results were: grade 0 (26; 70.3\%), grade I (7;
$18.9 \%)$, grade II (2; 5.4\%), grade III ( $2 ; 5.4 \%)$, grade IV (0). Associated injuries and their outcomes are listed in Table 5. Complications were categorized in four areas; postoperative infection, neurological sequelae, osteonecrosis of the femoral head, and heterotopic ossification. Early ICU care (first 24 hours) was significantly related with heterotopic ossification ( $p=0.025)$. Only intra-abdominal injury was significantly related with osteonecrosis of the femoral head ( $p=0.029$; odds ratio [OR], 30.00). Otherwise, there was no significant relationship with the outcomes. Femoral head fracture associated with acetabular fracture was significantly related with osteonecrosis of the femoral head ( $p=0.029$; OR, 30.00).

\section{Risk factors for functional outcomes (MDA)}

The model of the combination of age and operation time showed the best correlation with clinical results of the pa-

Table 5. The association between the associated injury and the outcome

\begin{tabular}{|c|c|c|c|c|}
\hline Associated injury & Postoperative infection & Neurological sequelae & Osteonecrosis of femoral head & Heterotopic ossification \\
\hline \multicolumn{5}{|c|}{ ICU care (first 24 hours) } \\
\hline$p$-value & 0.166 & 1.000 & 0.242 & $0.025^{\mathrm{a}}$ \\
\hline $\mathrm{OR}$ & 15.500 & & 7.500 & \\
\hline \multicolumn{5}{|l|}{ Head } \\
\hline$p$-value & 1.000 & 1.000 & 1.000 & 0.640 \\
\hline $\mathrm{OR}$ & & & & 1.556 \\
\hline \multicolumn{5}{|l|}{ Chest } \\
\hline$p$-value & 0.269 & 1.000 & 0.380 & 0.297 \\
\hline $\mathrm{OR}$ & 7.250 & & 3.500 & 4.125 \\
\hline \multicolumn{5}{|l|}{ Intra-abdominal } \\
\hline$p$-value & 1.000 & 1.000 & $0.029^{\mathrm{a}}$ & 0.575 \\
\hline OR & & & 30.000 & 2.444 \\
\hline \multicolumn{5}{|l|}{ Urogenital } \\
\hline$p$-value & 1.000 & 1.000 & 1.000 & 1.000 \\
\hline \multicolumn{5}{|l|}{ OR } \\
\hline \multicolumn{5}{|l|}{ Extremities } \\
\hline$p$-value & 0.519 & 1.000 & 0.306 & 0.258 \\
\hline OR & & 1.750 & 3.818 & 2.914 \\
\hline \multicolumn{5}{|c|}{ Femoral head fracture } \\
\hline$p$-value & 1.000 & 1.000 & $0.029^{\mathrm{a}}$ & 1.000 \\
\hline OR & & & 30.000 & 0.700 \\
\hline
\end{tabular}

ICU: intensive care unit, OR: odds ratio.

astatistically significant. 
Table 6. Multiple regression analysis

\begin{tabular}{|c|c|c|c|c|c|c|c|}
\hline Model & & $\mathrm{R}^{2}$ & DW & & B & $p$-value & VIF \\
\hline \multirow[t]{3}{*}{ MDA } & & & & Constant & 23.454 & 0.000 & \\
\hline & Age & 0.202 & & Age & -0.101 & 0.000 & 1.081 \\
\hline & Age, operation time & 0.391 & 1.889 & Operation time & -0.010 & 0.003 & 1.081 \\
\hline \multirow[t]{3}{*}{ Brooker grade } & & & & Constant & -1.142 & 0.001 & \\
\hline & Operation time & 0.402 & & Operation time & 0.005 & 0.000 & 1.001 \\
\hline & Operation time, ISS & 0.496 & 2.104 & ISS & 0.038 & 0.020 & 1.001 \\
\hline
\end{tabular}

DW: Durbin-Watson, VIF: variance inflation factor, MDA: Merle d'Aubigne and Postel, ISS: injury severity score.

tient (Table 6).

\section{Risk factors for heterotopic ossification (Brooker grade)}

The final multiple regression model has included operation time and ISS (Table 6).

\section{DISCUSSION}

Management of pelvic and acetabular fractures is one of the most challenging clinical problems for trauma surgeons. The overall mortality of these fractures ranges from 10-20\%, according to a previous report [1-3]. However, acetabular fractures have different natures, like pelvic ring fractures, especially in terms of mortality. The approximate mortality of acetabular fractures is reported to be around $1 \%[3,10]$. Therefore, studies on acetabular fractures have focused on factors of surgical treatment regarding functional outcome and complications [11-13]. Known factors associated with outcomes and complications include quality of reduction, age, fracture type, damage to the femoral head, associated injury, comorbidity, timing of surgery, and surgical approach [5]. Especially, quality of the reduction is a crucial factor $[5,8,14]$. If anatomical reduction is achieved, an excellent or good functional outcome can be estimated in $83-89 \%$ of patients [5]. However, this injury requires a multi-disciplinary approach, and we concentrated on other factors that may be of interest in non-orthopedic departments and reported our treatment results of this injury as the focused training center for trauma.

The mean age of the patients was $47.18( \pm 15.11)$ years, which was slightly higher than that of the previous me- ta-analysis by Giannoudis et al. [5], and the high proportion of men was similar. The most common injury mechanism was falling in our study; this result was different from other reports where road traffic accidents were the major mechanism in $80.5 \%$ of patients [5]. Mean ISS was $8.58( \pm 6.82)$ points and this was about $50 \%$ lower than in other reports [5,15-18], as we excluded patients with associated pelvic ring injuries. Fractures in the posterior wall and both columns were the most frequently observed in our study, which is in close agreement with studies by numerous authors [5,11-14,18-21]. Only one patient died because of sepsis and one patient had a co-morbidity of diabetes and chronic renal disease. A mortality rate of $2.6 \%$ was similar to the data of other studies, which was near 3\% [5]. In total, $24.3 \%$ were evaluated with a fair and poor grade of MDA, which was similar to other meta-analysis results $(20.6 \%)$ [5].

Fractures of the extremities was the most common associated injury followed by chest injury and head injury. This was similar to the report of other publications [20,22-24]. Most associated injuries were not associated with the outcome, and only intra-abdominal injuries were significantly associated with osteonecrosis of the femoral head. However, the clinical relevance of the abdominal injury and necrosis of the femoral head is poor due to the lack of site-to-region associations and lack of reports of related studies that have similar conclusions.

ICU care within the first 24 hours had shown statistical correlation with heterotopic ossification in our study. We postulate that associated injuries that required ICU care may have a relationship with heterotopic ossification. Ghalambor et al. [25] reported that the presence of associated injuries to the abdomen and chest were found 
to highly correlate with grade I ectopic bone formation. Damage to the abdomen and chest may lead to an unstable vital sign that requires ICU care. Thus, these results are in close agreement with our result.

Avascular necrosis of the femoral head (AVN) is a late complication of this injury, and it requires additional replacement arthroplasty, that is, long-term failure of fixation. Thus, it is crucial to evaluate factors related to this. An overall incidence of 5.6\% was reported in another meta-analysis [5]. In our study, the incidence of AVN was $8.1 \%$, which is slightly higher. Multiple factors were related to these complications: posterior fracture dislocation at the time of injury, the time interval between dislocation of the hip, and reduction and delayed operative treatment. These factors were not evaluated in this study. However, we found a strong correlation between fracture of the femoral head itself and AVN. This result is in close agreement with those of numerous authors $[5,26]$.

MDA is one of the most commonly used clinical scoring systems for the evaluation of functional results of this injury [5]. Many studies have investigated the association of MDA with this type of fracture and the quality of reduction [5,27-29]. In these papers, simple fractures showed a good functional outcome for associate fracture patterns and poor functional outcomes when reduction was unsatisfactory. We estimated the linear relationship between MDA and other numerical data as factors using a multiple regression analysis. It appears that the combination of age and operation time negatively correlated with MDA. ISS, intraoperative blood loss, and pints of pRBCs were not correlated with MDA. Results of present studies correspond with the results of Murphy et al. [14], which reported that both increasing age and associated fracture type had a strong association with poor outcomes. Moreover, the more complex of the fracture, the longer an operation may take.

The Brooker classification was used to classify heterotopic ossification. The Brooker grade of heterotopic ossification is associated with clinical outcome. The higher the grade, the higher the degree of heterotopic ossification, which has been reported to be associated with poor clinical outcomes $[9,25,30]$. In our analysis, both operation time and ISS are associated with this grade. This result is in close agreement with those of previous studies. Ac- cording to a study by Ghalambor et al. [25], grade I ectopic bone formation shows a significant correlation with associated injuries to the abdomen and the chest. They also reported that the extended approach, the presence of multiple perifracture operative findings, and T-type fractures were correlated with grade I heterotopic ossification. An ISS of $\geq 16$ ( $p=0.02$; OR, 2.2) was also reported as a risk factor for heterotopic ossification in high-energy wartime extremity wounds in the study by Forsberg et al [31]. These results indicate that if a patient with an acetabular injury, high ISS, and complex fracture pattern may have a poor clinical outcome, especially considering range of motion limitations, which have a close relationship with heterotopic ossification.

This study has important limitations; however, most come from its small number of patients and retrospective design. Relating statistical significance data with the clinical outcomes is difficult in the study of pelvic and acetabular fractures, as already mentioned by Matta [32]. He stated that authors should not wrongly include patients with inadequate data. Therefore, we tried to enforce strict enrollment policies. Patients who did report with the 1 year of follow-up, or those with missing data, were excluded. In addition, there were seven patients who experienced pelvic ring fractures associated with acetabular fractures who were excluded, since this can be a considerable confounding factor. Another limitation of this study was that surgical factors such as quality of reduction, timing of surgery, and surgical approach were not included. These well-known factors should be considered, which may lead to more careful conclusions. This should be complemented by subsequent studies.

\section{CONCLUSION}

Fractures of acetabulum are complex and often have multiple associated injuries. Despite the high incidence of associated injuries, the clinical outcomes were not significantly affected. The increase in age and operation time was a co-factor that negatively affected the clinical outcome of this fracture treatment. In addition, the increased operation time and injury severity score were suggested to increase the Brooker grade, which indicates heterotopic 
ossification after surgical management of this fracture.

\section{REFERENCES}

1. Bircher M, Giannoudis PV. Pelvic trauma management within the UK: a reflection of a failing trauma service. Injury 2004;35:2-6.

2. Riemer BL, Butterfield SL, Diamond DL, Young JC, Raves JJ, Cottington E, et al. Acute mortality associated with injuries to the pelvic ring: the role of early patient mobilization and external fixation. J Trauma 1993;35:671-5; discussion 676-7.

3. Dalal SA, Burgess AR, Siegel JH, Young JW, Brumback RJ, Poka A, et al. Pelvic fracture in multiple trauma: classification by mechanism is key to pattern of organ injury, resuscitative requirements, and outcome. J Trauma 1989;29:981-1000; discussion 1000-2.

4. Hauschild O, Strohm PC, Culemann U, Pohlemann T, Suedkamp NP, Koestler W, et al. Mortality in patients with pelvic fractures: results from the German pelvic injury register. J trauma 2008;64:449-55.

5. Giannoudis PV, Grotz MR, Papakostidis C, Dinopoulos H. Operative treatment of displaced fractures of the acetabulum. A meta-analysis. J Bone Joint Surg Br 2005;87:2-9.

6. Bhandari M, Matta J, Ferguson T, Matthys G. Predictors of clinical and radiological outcome in patients with fractures of the acetabulum and concomitant posterior dislocation of the hip. J Bone Joint Surg Br 2006;88:1618-24.

7. Centers for Disease Control and Prevention (CDC). Surgical Site Infection (SSI) Event Procedure-associated Module [Internet]. Seoul: CDC 2017 [cited 2018 Nov 1]. Available from: www. cdc.gov/nhsn/PDFs/pscmanual/9pscssicurrent.pdf.

8. Letournel E. Acetabulum fractures: classification and management. Clin Orthop Relat Res 1980;(151):81-106.

9. Brooker AF, Bowerman JW, Robinson RA, Riley LH Jr. Ectopic ossification following total hip replacement. Incidence and a method of classification. J Bone Joint Surg Am 1973;55:1629-32.

10. Laird A, Keating JF. Acetabular fractures: a 16-year prospective epidemiological study. J Bone Joint Surg Br 2005;87:969-73.

11. Meena UK, Tripathy SK, Sen RK, Aggarwal S, Behera P. Predictors of postoperative outcome for acetabular fractures. Orthop Traumatol Surg Res 2013;99:929-35.

12. Moed BR, Paul HY, Gruson KI. Functional outcomes of acetabular fractures. J Bone Joint Surg Am 2003;85:1879-83.
13. Borrelli J Jr, Goldfarb C, Ricci W, Wagner JM, Engsberg JR. Functional outcome after isolated acetabular fractures. J Orthop Trauma 2002;16:73-81.

14. Murphy D, Kaliszer M, Rice J, McElwain JP. Outcome after acetabular fracture. Prognostic factors and their inter-relationships. Injury 2003;34:512-7.

15. Goulet JA, Bray TJ. Complex acetabular fractures. Clin Orthop Relat Res 1989;(240):9-20.

16. Cole JD, Bolhofner BR. Acetabular fracture fixation via a modified Stoppa limited intrapelvic approach. Description of operative technique and preliminary treatment results. Clin Orthop Relat Res 1994;(305):112-23.

17. Starr AJ, Watson JT, Reinert CM, Jones AL, Whitlock S, Griffin DR, et al. Complications following the "T extensile" approach: a modified extensile approach for acetabular fracture surgery-report of forty-three patients. J Orthop Trauma 2002;16:535-42.

18. Stöckle U, Hoffmann R, Südkamp N, Reindl R, Haas NP. Treatment of complex acetabular fractures through a modified extended iliofemoral approach. J Orthop Trauma 2002;16:220-30.

19. Briffa N, Pearce R, Hill AM, Bircher M. Outcomes of acetabular fracture fixation with ten years' follow-up. J Bone Joint Surg Br 2011;93:229-36.

20. Liebergall M, Mosheiff R, Low J, Goldvirt M, Matan Y, Segal D. Acetabular fractures. Clinical outcome of surgical treatment. Clin Orthop Relat Res 1999;(366):205-16.

21. Porter SE, Schroeder AC, Dzugan SS, Graves ML, Zhang L, Russell GV. Acetabular fracture patterns and their associated injuries. J Orthop Trauma 2008;22:165-70.

22. Matta JM, Anderson LM, Epstein HC, Hendricks P. Fractures of the acetabulum. A retrospective analysis. Clin Orthop Relat Res 1986;(205):230-40

23. Webb LX, Bosse MJ, Mayo KA, Lange RH, Miller ME, Swiontkowski MF. Results in patients with craniocerebral trauma and an operatively managed acetabular fracture. J Orthop Trauma 1990;4:376-82.

24. Dong JL, Zhou DS. Management and outcome of open pelvic fractures: a retrospective study of 41 cases. Injury 2011;42:10037.

25. Ghalambor N, Matta JM, Bernstein L. Heterotopic ossification following operative treatment of acetabular fracture. An analysis of risk factors. Clin Orthop Relat Res 1994;(305):96-105.

26. Tscherne H, Pohlemann T. Tscherne Unfallchirurgie: becken und acetabulum. 4th ed. Heidelberg: Springer; 1998.

27. Matta JM. Fractures of the acetabulum: accuracy of reduction 
and clinical results in patients managed operatively within three weeks after the injury. J Bone Joint Surg Am 1996;78:1632-45.

28. Mears DC, Velyvis JH, Chang CP. Displaced acetabular fractures managed operatively: indicators of outcome. Clin Orthop Relat Res 2003;(407):173-86.

29. Moed BR, WillsonCarr SE, Watson JT. Results of operative treatment of fractures of the posterior wall of the acetabulum. J Bone Joint Surg Am 2002;84-A:752-8.

30. Pohl F, Seufert J, Tauscher A, Lehmann H, Springorum HW,
Flentje M, et al. The influence of heterotopic ossification on functional status of hip joint following total hip arthroplasty. Strahlenther Onkol 2005;181:529-33.

31. Forsberg JA, Pepek JM, Wagner S, Wilson K, Flint J, Andersen $\mathrm{RC}$, et al. Heterotopic ossification in high-energy wartime extremity injuries: prevalence and risk factors. J Bone Joint Surg Am 2009;91:1084-91.

32. Matta JM. Striving for statistical significance: how important is it? J Orthop Trauma 2000;14:227-9. 